\title{
Study of a large-scale dry slab avalanche and the extent of damage to a cedar forest in the Makunosawa valley, Myoko, Japan
}

\author{
Yukari TAKEUCHI, ${ }^{1}$ Hiroyuki TORITA, ${ }^{2}$ Koichi NISHIMURA, ${ }^{3}$ Hiroyuki HIRASHIMA ${ }^{4}$ \\ ${ }^{1}$ Tohkamachi Experimental Station, Forestry and Forest Products Research Institute, Tohkamachi 948-0013, Japan \\ E-mail: yukarit@affrc.go.jp \\ ${ }^{2}$ Forest Research Department, Hokkaido Research Organization, Koshunai-cho, Bibai 079-0166, Japan \\ ${ }^{3}$ Graduate School of Environmental Studies, Nagoya University F3-1(200), Furo-cho, Chikusa-ku, Nagoya 464-8601, Japan \\ ${ }^{4}$ Snow and Ice Research Center, National Research Institute for Earth Science and Disaster Prevention, Suyoshi, \\ Nagaoka 940-0821, Japan
}

\begin{abstract}
Accurate measurements of snow avalanche flows in forests are rare. To understand how forests can stop avalanches, we study a mixed flowing avalanche that stopped in a cedar (Cryptomeria japonica) forest in Japan. The large-scale dry slab avalanche occurred in the Makunosawa valley in Myoko on 17 February 2008 and damaged many trees. The site contains a geophone and other devices to detect avalanche activity. A nearby meteorological station provides weather information. Post-event observations were made of the scale of the avalanche and tree damage. These showed that the avalanche released from the east-southeast-facing slope at $1700 \mathrm{ma}$ a.s.l. Snow debris reached $\sim 770 \mathrm{~m}$ a.s.l; the horizontal runout distance was $\sim 3000 \mathrm{~m}$. The area of the runout zone was $\sim 10 \mathrm{ha}$, and the snow water equivalent of debris was $400-1500 \mathrm{~mm}$. The mass of the avalanche was roughly estimated at 5-10 $\times 10^{7} \mathrm{~kg}\left(1-2 \times 10^{5} \mathrm{~m}^{3}\right)$. We used snowpack simulation models to estimate the height of the fracture zone. The simulations revealed that a faceted snow layer formed at $\mathbf{2} \mathbf{m}$ and the stability index was 0.5 (poor) at the time of the avalanche release, due to heavy snowfall. We estimated the avalanche velocity from the bending stress of the broken cedar trees, in order to verify the effect of forests in reducing avalanche velocity. The avalanche was estimated to flow into the forest at a velocity of $>26-31 \mathrm{~m} \mathrm{~s}^{-1}$, with a $17 \mathrm{~m}$ high powder snow layer and a dense-flow layer $<2 \mathrm{~m}$ in height. It appears to have slowed down and stopped at $\sim 130 \mathrm{~m}$ after penetrating the upper edge of the forest.
\end{abstract}

\section{INTRODUCTION}

Mountain forests have two major roles in avalanche protection. The first is to prevent avalanches from starting and the second is to decelerate and stop small, frequent flowing avalanches. A forest on a steep slope can inhibit avalanche formation because it influences the character of the snowpack by intercepting incoming/outgoing radiation, interrupting snow transportation by wind and intercepting snowfall. Snow released from tree crowns as lumps and meltwater produces an irregular snowpack structure. Tree trunks may also support the snowpack. These effects inhibit the formation of slab avalanches (in der Gand, 1981; Gubler and Rychetnik, 1991; McClung and Schaerer, 2006).

The second use of mountain forests, that of breaking small frequent avalanches, has not been investigated in detail. Since large flowing avalanches can easily destroy large tracts of mountain forests, they are almost unaffected by trees. The energy required to fracture, uproot and entrain trees is small compared with the total potential energy of an avalanche, especially when the avalanche is large (Bartelt and Stöckli, 2001). In fact, the damage potential of large avalanches with tree debris may even be larger because of the increase in high-density mass within the avalanche. However, the role of forests in stopping small and medium-sized avalanches remains difficult to assess.

Avalanche dynamics models including avalanche size and tree effects have not been studied in detail except for an initial study by Bartelt and Stöckli (2001). That study presented a simple center-of-mass avalanche model that applies the principle of conservation of energy to calculate the deceleration of avalanches caused by tree fracture, overturning and debris entrainment. The calculated results revealed that tree entrainment slows down an avalanche more than tree fracture, depending on the mass of the root system mobilized during tree upheaval and entrainment.

Avalanche dynamics models have included the effects of forests (Christen and others, 2010). Simulations reveal that even if forests cannot reduce the runout distances of large avalanches, they can prevent the lateral spreading of avalanches, reducing the inundation area. These results are based on ad hoc selection of friction parameters. Therefore, fundamental problems remain in understanding how forests reduce the speed of avalanches. The question what kinds of forests provide the maximum protection against snow avalanches is unanswered. Clearly, more instrumented observations of avalanches and forest damage are required to solve these problems.

In 2008, we had the unique opportunity to obtain a dataset of an avalanche with forest damage from the Makunosawa valley, Myoko, Japan. A large-scale dry slab avalanche occurred in the valley on 17 February 2008 and damaged many trees (Fig. 1; Takeuchi and others, 2009, 2010). Snow avalanches have often occurred in the Makunosawa valley, so it is ideally suited for studying how meteorological elements influence avalanche activity. Since 2000, five large-scale snow avalanches with a running distance exceeding $2000 \mathrm{~m}$ have been observed and some characteristics of avalanches in this valley have been obtained from the 11 winter seasons up to 2010 (Takeuchi and others, 2002, 2003; Takeuchi, 2010). 

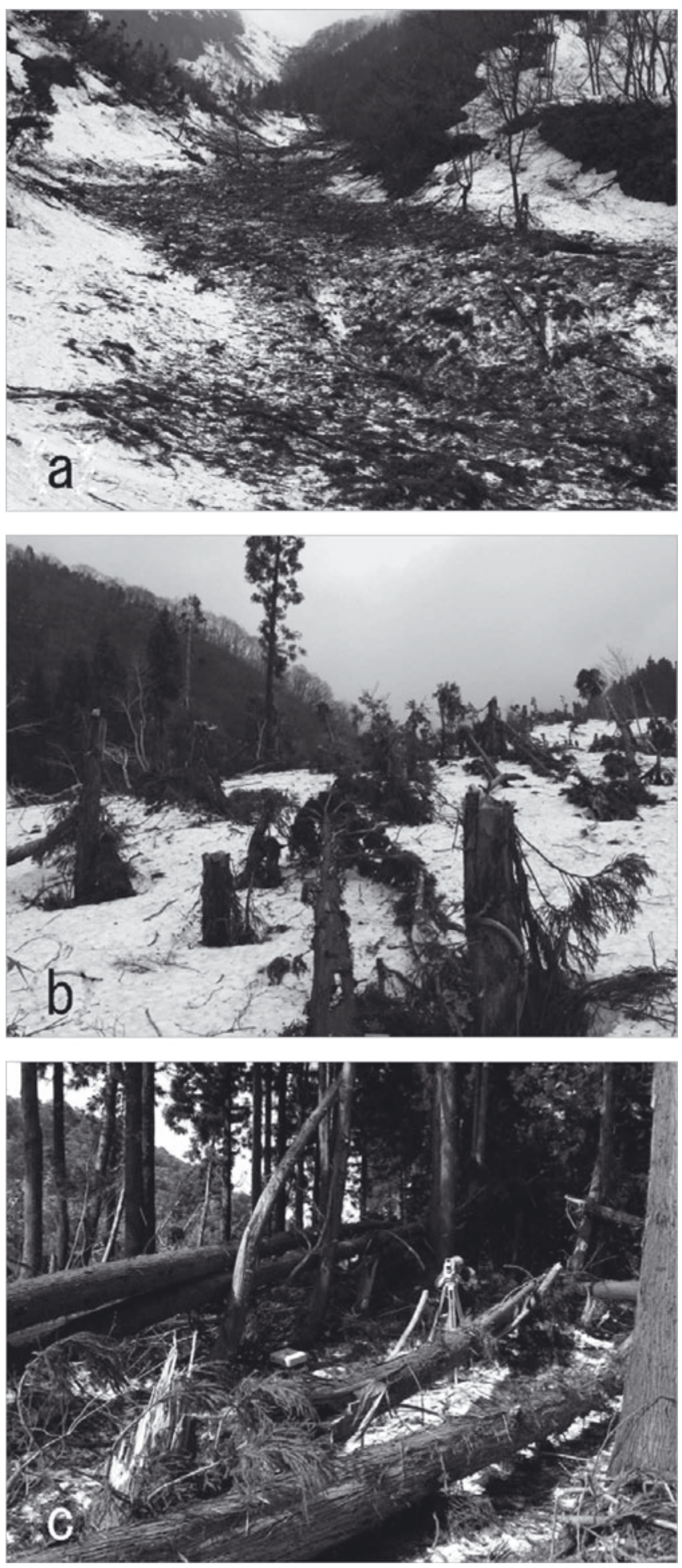

Fig. 1. Avalanche damage to cedar trees in the Makunosawa valley in 2008. (a) Cedar leaves and branches appeared on the debris surface in the melt season. (b, c) Broken and fallen cedar trees from the avalanche.

The 17 February 2008 avalanche was the largest of the five observed. It was the only event that damaged large tracts of forest. During the melt season in April, many trees broken by the avalanche appeared on the surface and we found that the avalanche seemed to stop in the cedar (Cryptomeria japonica) forest and not pass through the forest. Therefore, we were able to investigate the extent of damage to the cedar forest and attempted to estimate the avalanche velocity in the forest from the bending stress of the broken cedar trees. The purpose was to verify the effect of forests in reducing avalanche velocity.

The role of mountain forests in stopping avalanches is an important problem in Japan. There have been several reports on forest damage caused by snow avalanches in Japan (e.g. Saeki, 1975). The path and form of movement of avalanches has been determined according to the tree damage (Shimokawa, 1983). Johnson and others (1982) estimated the maximum wind velocity of hurricanes based on tree damage. However, we know of no studies that have estimated avalanche velocity in the same way. We analyzed the position and damage of each tree and were thus able to estimate the avalanche velocity in the forest.

In this paper, we present two results regarding snow avalanche activity in mountain forests. Firstly, we present general information regarding the occurrence of a very large-scale avalanche, including the meteorology leading up to the avalanche, the extent of the runout zone and the mass of debris. Secondly, we report details of forest damage and estimate the avalanche velocity in the forest.

\section{SITE AND METHODS}

The Myoko area including Makunosawa valley $\left(36^{\circ} 54^{\prime} \mathrm{N}\right.$, $138^{\circ} 10^{\prime} \mathrm{E}$ ) is located on the Sea of Japan side in the center of the main island (Honshu) of Japan. It is one of the heaviest snowfall areas in Japan, where the northwesterly monsoon conveys heavy snowfalls in winter. The depth of daily new snowfall sometimes exceeds $1 \mathrm{~m}$, and the annual maximum snow depth is $>4 \mathrm{~m}$ in the valley. Makunosawa valley starts near the peak of Mount Kanna and faces east (Fig. 2). The altitude at the top of the valley is $1740 \mathrm{~m}$. The valley slope generally increases with altitude. It is $35-40^{\circ}$ at the highest part, which is the starting zone of the large-scale avalanches.

Avalanches were detected by a geophone, video camera and a snow avalanche detection system located in the Makunosawa valley. A geophone $(G)$ was set up on the avalanche path and recorded vertical tremors of ground motion caused by avalanches. A snow avalanche detection system consists of detection poles and a signal conversion device. Two detection poles, $\mathrm{D}_{1}$ and $\mathrm{D}_{2}$, were installed on the avalanche path and subjected to avalanche impact with built-in vibration sensors (likura and others, 2000). A video camera $(\mathrm{V})$ was set up to record the process of avalanche release and flow. Meteorological elements (air temperature, precipitation and snow depth) were measured at a meteorological station, $M$, where the altitude is $810 \mathrm{~m}$. $V$ and $M$ are not on the avalanche path and are safe from avalanches (Fig. 2). In addition, data on sunshine duration and wind speed at the site nearest the Makunosawa valley of the Automated Meteorological Data Acquisition System (AMeDAS) of the Japanese Meteorological Agency (Sekiyama; $350 \mathrm{~m}$ a.s.l.) were obtained for the simulation of the snowpack model.

We confirmed the avalanche in the Makunosawa valley on 22 February 2008, 5 days after it occurred. The fracture line of the flank was seen in the highest part of the valley, and the starting zone of the avalanche seemed to be the eastsoutheast-facing slope around $1700 \mathrm{~m}$ a.s.l.

The debris was surveyed in April to understand the deposited mass and the extent of the runout zone of the avalanche. Before the debris snow began to melt, a pit observation of debris was made at the center of the runout 
zone (point A), and the density, liquid water content, hardness and snow water equivalent of debris were measured. To estimate the snow water equivalent of the debris, snow cores were taken using a Kamuro-type snow sampler (cross-sectional area $20 \mathrm{~cm}^{2}$ ) at ten points along the longitudinal line of the runout zone, and the thickness and mass of the debris layer in each snow core were measured. The positions of the measurements were recorded by GPS. The furthest reach of debris and the lateral edge of debris were recorded by GPS, when many leaves and branches carried by the avalanche and buried in the debris appeared on the surface due to melting (Fig. 1a).

In May, after the snow had disappeared, tree damage in the cedar forest in the runout zone was investigated. The cedar trees were planted in 1947. The distance from the avalanche starting point to the upper part of the forest is $\sim 2700 \mathrm{~m}$. The area of investigation $(17 \mathrm{~m}$ wide and $130 \mathrm{~m}$ long; Fig. 3a) was fixed and all trees in the area were measured. The items measured were the tree height, height of the lowest branch, breaking height of the trunk, trunk diameter at the breaking height, diameter at breast height, and position of the tree. The height of the lowest branch (see Fig. 6 left, further below) is the lowest height at which branches survive on both sides of the trunk, and implies the height (thickness) of the avalanche. Trees with lower branches newly broken by the avalanche were measured and uninjured trees were excluded.

\section{RESULTS}

\section{Time of avalanche release}

The time of the avalanche release was $1348 \mathrm{~h}$ on 17 February according to the data of the geophone, the avalanche detection system and the video camera. Obvious tremor data were recorded for $\sim 30 \mathrm{~s}$ by the geophone, and the maximum amplitude of the tremor velocity exceeded $3000 \times 10^{-6} \mathrm{~m} \mathrm{~s}^{-1}$. Pulse signals were recorded for $\sim 15 \mathrm{~s}$ by the avalanche detection system. The avalanche could not be photographed due to very low visibility on account of the heavy snowfall; only snow powder blowing toward the camera could be taken at that time.

\section{Meteorology preceding avalanche}

The air temperature, snow depth, precipitation and sunshine duration during the 7 days before the avalanche release are shown in Figure 4. The weather cleared up and the air temperature exceeded $0^{\circ} \mathrm{C}$ on 11 February. Snowfall started the next morning, and $2-3 \mathrm{~cm}$ of new snow was deposited on the evening of the 12th. The air temperature dropped rapidly in the evening, decreasing to $-9.2^{\circ} \mathrm{C}$ before the dawn of the 13th. At the same time, snowfall increased and the snow depth increased rapidly. The total precipitation from 12 February to the time of the avalanche release was $174 \mathrm{~mm}$, and the snow depth increased from $225 \mathrm{~cm}$ to $381 \mathrm{~cm}$. The air temperature when the avalanche released was $-6.7^{\circ} \mathrm{C}$.

\section{Runout zone and path}

The farthest reach of debris was $\sim 770$ ma.s.l., and the horizontal runout distance was $3000 \mathrm{~m}$ from the top of the starting zone. The starting zone and runout zone are shown in the topographic map (Fig. 3). The area surrounded by a
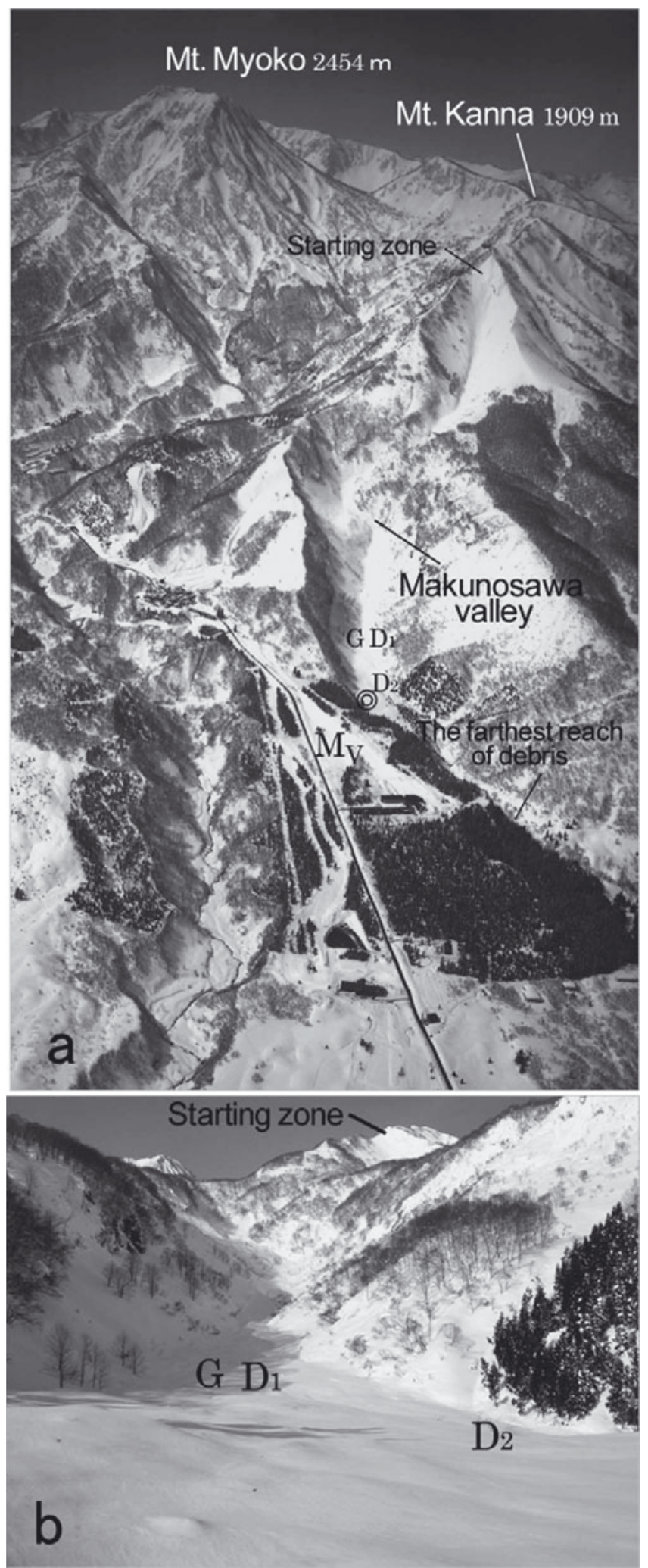

Fig. 2. (a) Overview of Makunosawa valley. (b) Runout zone taken at the point $\odot$ in (a). G: geophone; $D_{1}$ and $D_{2}$ : snow avalanche detection systems; M: meteorological station; V: video camera.

solid line indicates the runout zone where we confirmed debris. It was estimated at $\sim 10$ ha.

According to the positions and directions of fallen trees, the avalanche seems to have separated, with part of it flowing straight over the ridge as shown by the dotted line (Fig. 3). 

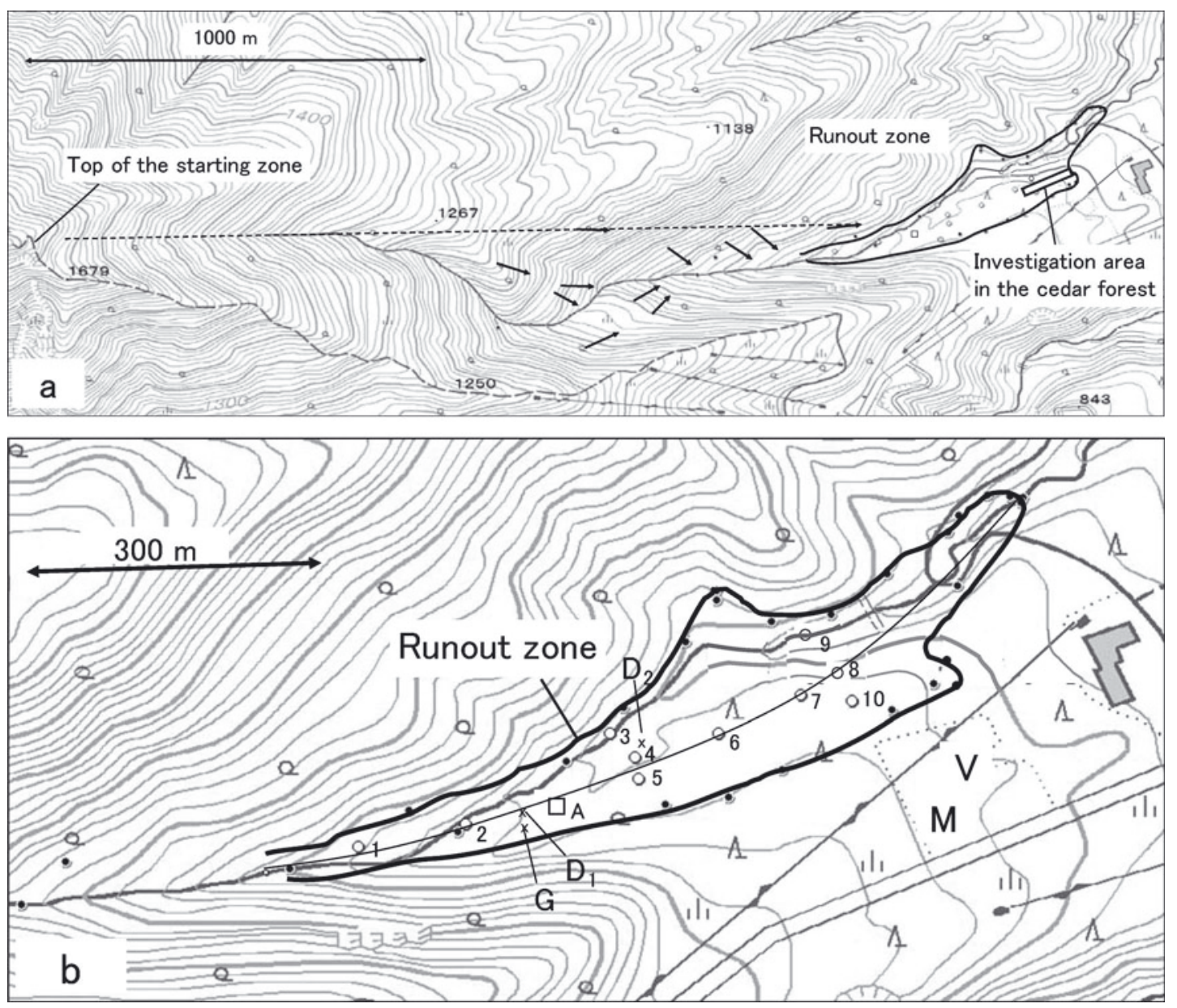

Fig. 3. (a) Topographic map of the Makunosawa valley. Arrows indicate the direction of fallen trees, i.e. the flow direction of the avalanche. The dotted line is an extension of the facing direction of the starting zone. (b) Runout zone and the positions of debris survey. G: geophone; $\mathrm{D}_{1}$ and $\mathrm{D}_{2}$ : snow avalanche detection systems; $\mathrm{M}$ : meteorological station; $\mathrm{V}$ : video camera.

\section{Water equivalent of debris}

In the results of the pit observation of debris, the snow depth was $349 \mathrm{~cm}$ and the debris depth was $319-174 \mathrm{~cm}$; the thickness was $145 \mathrm{~cm}$. The debris layer included many snow blocks of various sizes up to $\sim 1 \mathrm{~m}$. This corresponds to observed dry and wet snow avalanche deposits in Switzerland (Bartelt and McArdell, 2009). Most of the debris had become granular snow and the liquid water content was $8-10 \%$ (9\% on average).

The debris thicknesses are shown in Figure 5. Since the granular snow deposited after the avalanche remained on the debris at all points, we considered the debris had not yet melted. As the debris should not include any liquid water at first, the $9 \%$ liquid water was considered to be filtrated meltwater and rain. The water equivalent of the original debris was estimated at $400-1500 \mathrm{~mm}$ (1000 mm on average) by excluding the $9 \%$ liquid water from the mass of debris.

\section{Extent of cedar forest damage}

A total of 130 trees within the fixed area were investigated, and we found that 12 were uninjured, 48 were upright with only the branches broken, 11 were leaning, 13 were broken and fallen, 22 were stumps without fallen trunks and 24 were fallen trunks without stumps (Fig. 6). Ninety-five per cent (123) were cedar trees, and only the cedar tree data were used in this study. The cedar tree heights were $3.5-22.2 \mathrm{~m}$ (15.5 $\mathrm{m}$ on average), and the diameters at breast height were
$0.14-0.56 \mathrm{~m}$ (0.38 $\mathrm{m}$ on average). Damage to the cedar trees was most severe near the upper edge of the forest. It gradually decreased, and the rate of uninjured trees increased, the further we went into the forest. The direction in which the trees had fallen indicated the avalanche track (Fig. 7).

Near the upper edge of the forest the height of the lowest branch was $\sim 17 \mathrm{~m}$. This decreased the further we went into the forest, and indicated the avalanche height decrease (Fig. 8). The trunk diameter at the break height was $\sim 0.70 \mathrm{~m}$ near the upper edge of the forest. This also decreased the further we went into the forest (Fig. 9). The decreasing tendency was not observed in the diameters at breast height of trees that were not broken (+ in Fig. 9). Therefore the decrease in trunk diameter at the break height appears to be caused by a decrease in avalanche velocity and impact force in the forest. In Figure 9, 32 (97\%) of the broken trunks are located at $<70 \mathrm{~m}$ from the upper edge of the forest. The avalanche seems to have advanced $70 \mathrm{~m}$, breaking many trunks and high branches, and then to have broken only three thinner trunks and lower branches (Figs 8 and 9) in its continued advance. This suggests it was decelerating within the forest. No tendency can be seen in the relationship between the distance from the upper edge of the forest and the breaking height of the trunk (Fig. 10). The mean of the breaking height was $1.2 \mathrm{~m}$, and many more trunks were broken at the lower height than at the snow surface height of $3.8 \mathrm{~m}$. 

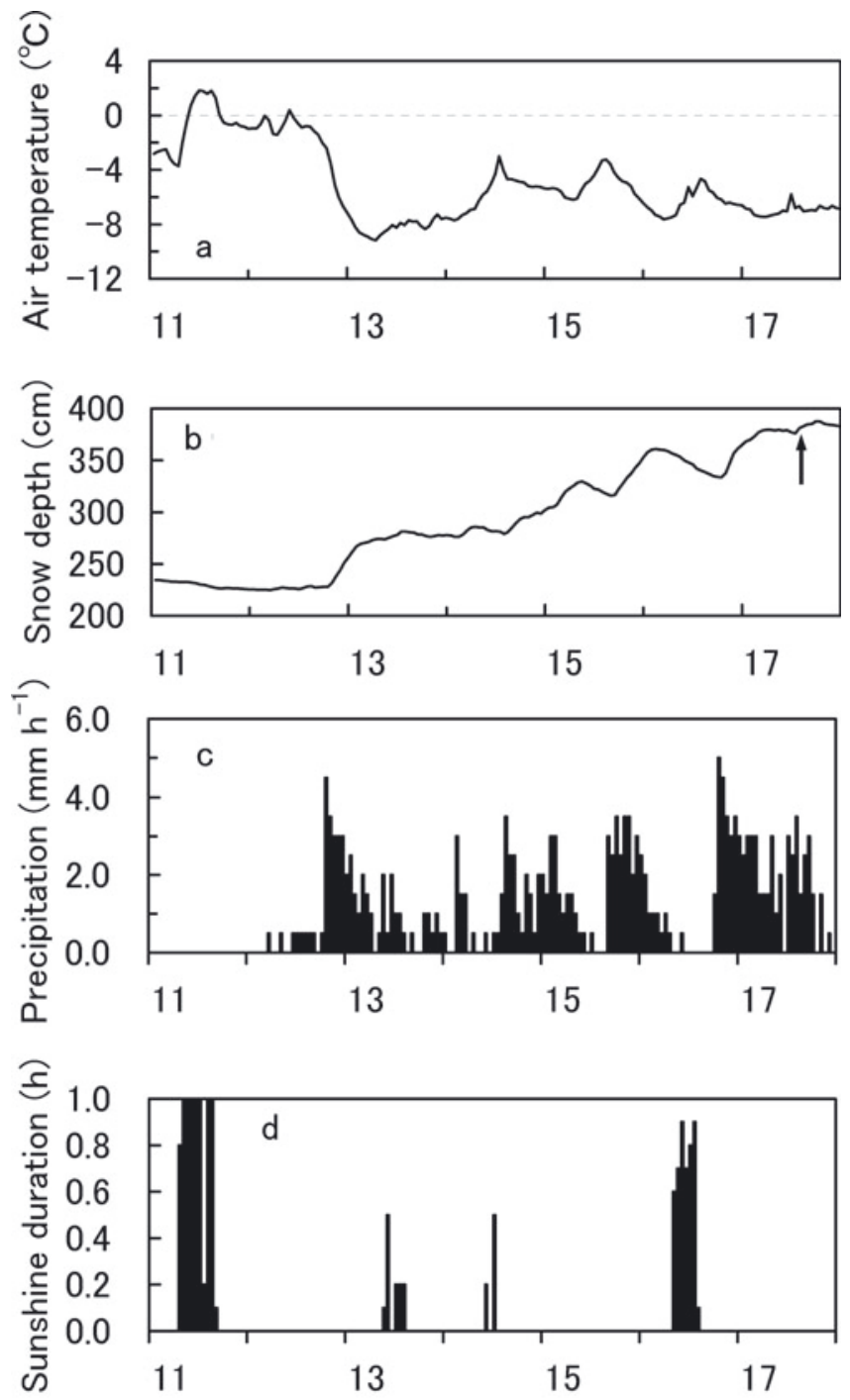

Date (Feb 2008)

Fig. 4. Meteorology from 11 to 17 February 2008. (a) Air temperature, (b) snow depth and (c) precipitation at $810 \mathrm{~m}$ a.s.I. (d) Sunshine duration at $350 \mathrm{~m}$ a.s.l. Arrow indicates the time of avalanche release.

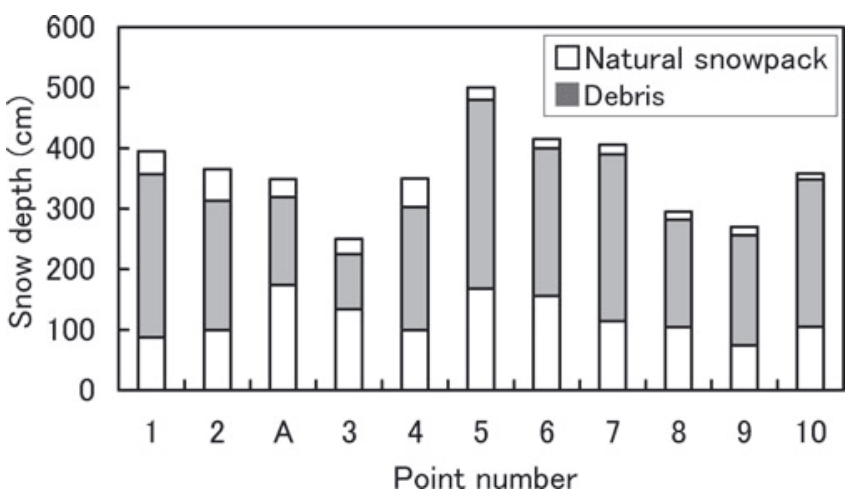

Fig. 5. Thickness of debris and natural snowpack at 11 points in the runout zone.

\section{DISCUSSIONS}

\section{Snowpack estimation in the starting zone}

As it was difficult to carry out a pit observation in the starting zone, the snow type and stability index of the snowpack were estimated using a snowpack model. The SNOWPACK model was developed by Bartelt and Lehning (2002) and applied by Lehning and others $(2002 a, b)$ for the Swiss avalanche warning. The parameterization of shear strength was improved based on the data in heavy-snowfall areas of Japan by Hirashima and others (2008). We simulated the snow profile and stability index (SI) using this improved model. The $\mathrm{SI}$ is the shear strength divided by the shear stress. Hirashima and others (2008) estimate the stability index from the shear strength formulated by Yamanoi and Endo (2002) and Abe and others (2006).

Meteorological data (air temperature, precipitation, snow depth, sunshine duration and wind speed) were used as input data for the simulation. Air temperature was corrected for the starting zone altitude ( $1700 \mathrm{ma}$ a.s.l.) considering a lapse rate of $6.5 \times 10^{-3}{ }^{\circ} \mathrm{Cm}^{-1}$. The slope angle was inputted as $40^{\circ}$ and the direction was southeast in the simulation. In the results, the surface snow had melted due to solar radiation on 11 February, and faceted grains then formed on the refrozen layer at $2 \mathrm{~m}$ (Fig. 11a). Because snow had been deposited on the faceted snow layer right after that, the minimum SI of snowpack decreased to 0.5, which is highly susceptible to avalanche release (Fig. 11b). Accordingly, the sliding surface of the avalanche was presumed to be the faceted snow which formed on 13 February and remained in the snowpack until 17 February.
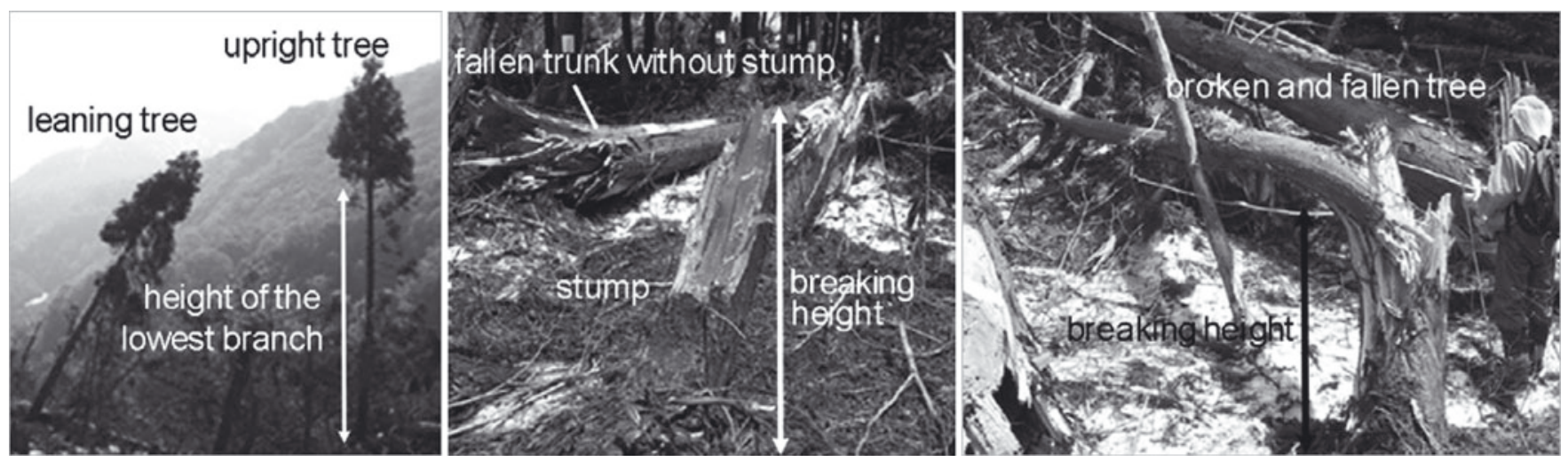

Fig. 6. Damage to the cedar trees. 

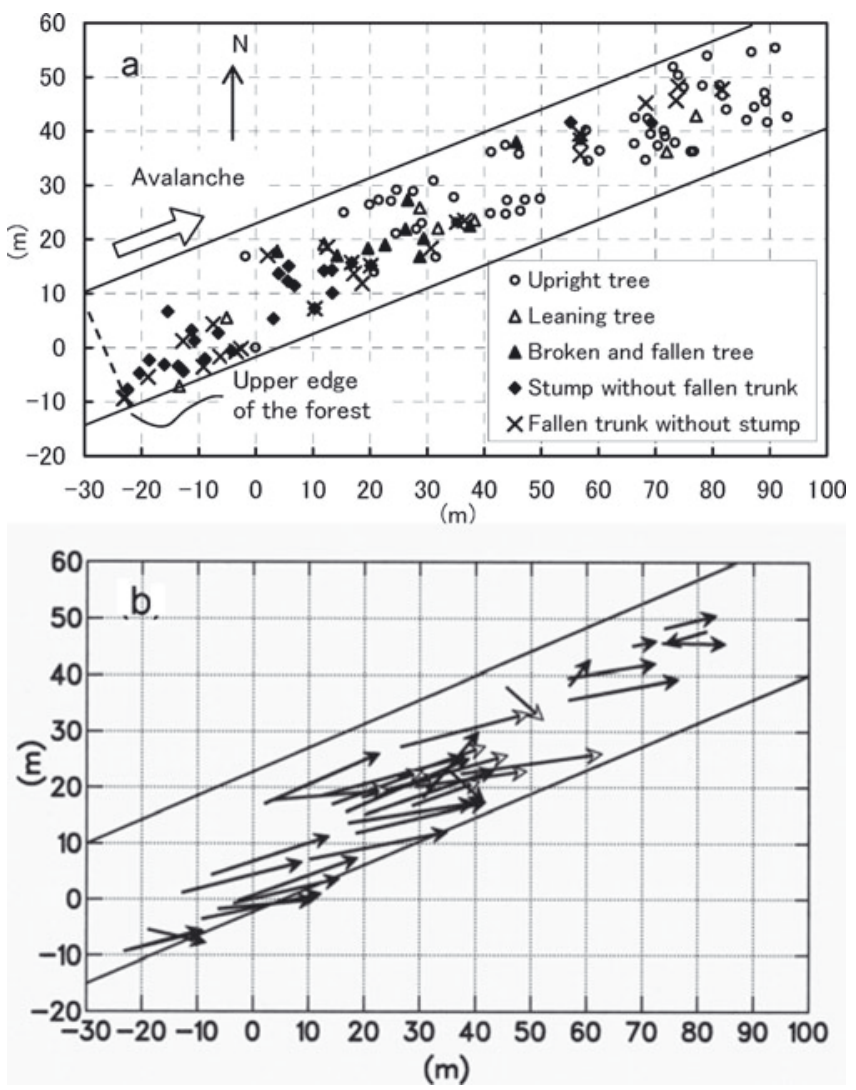

Fig. 7. (a) Positions and damage of cedar trees in the investigation area. (b) The directions of fallen trunks. White arrows are fallen trunks with stumps; black arrows are fallen trunks without stumps.

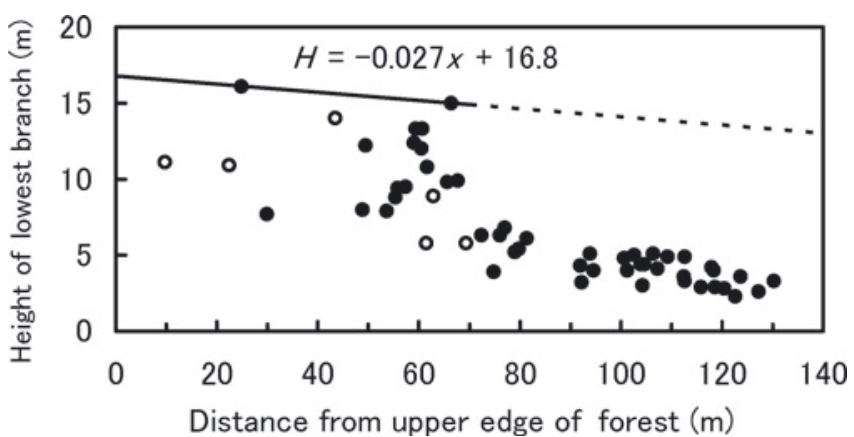

Fig. 8. Relationship between height of the lowest branch and distance from the upper edge of the forest. •: upright tree, $\bigcirc$ : leaning tree.

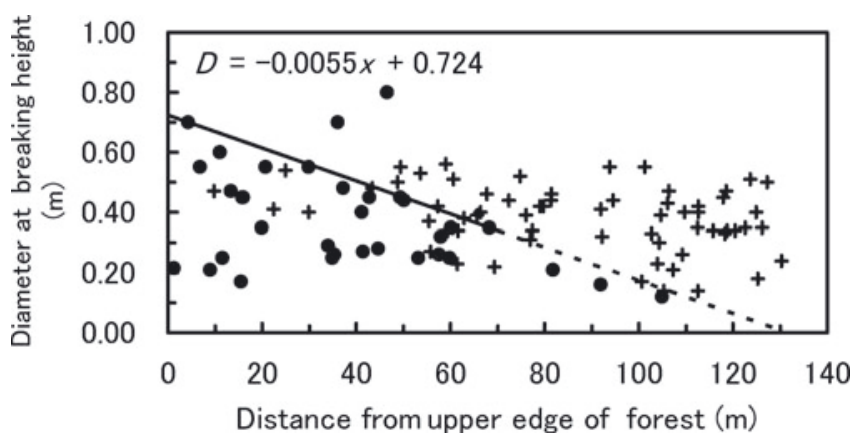

Fig. 9. Relationship between trunk diameter at the breaking height and distance from the upper edge of the forest. + : diameters at breast height of trees that were not broken.

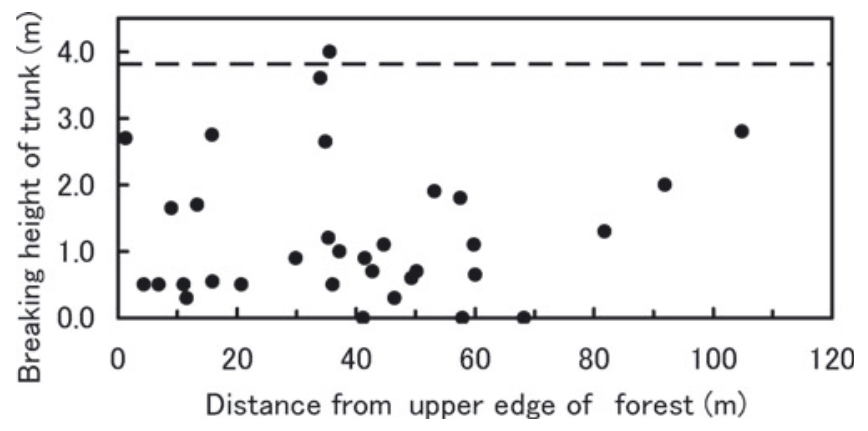

Fig. 10. Relationship between breaking height of the trunk and distance from the upper edge of the forest. The dashed line indicates the height of the snow surface $(3.8 \mathrm{~m})$

\section{Avalanche mass estimation}

We have estimated the avalanche mass very roughly based on the snow water equivalent of debris measured at 11 points. The method chosen to estimate the avalanche mass depends on the circumstances. For example, Vallet and others (2001) obtained volume measurements before and after the avalanche triggering by photogrammetric methods. They measured the release and deposition volumes of largescale avalanches and proved that avalanches entrain a large amount of snow along the avalanche track. Sovilla and others (2001) carried out manual measurements of the mountain snowpack from the starting zone to the deposition zone for four avalanche events in order to investigate mass entrainment and deposition processes. The mass-balance analysis of the four events showed that the deposition
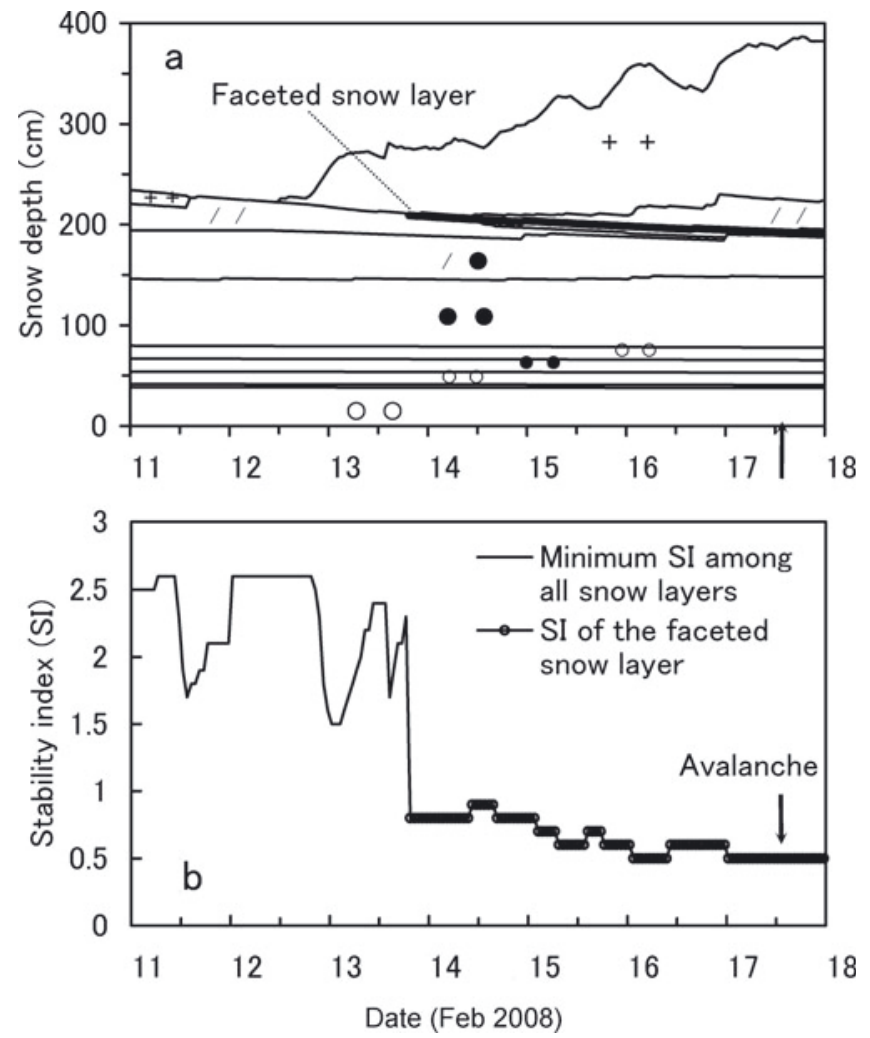

Fig. 11. Snow profile and stability index (SI) at the starting zone (1700 ma.s.I.) simulated by SNOWPACK model. The thick line in (a) indicates a faceted snow layer. +: new snow, /: lightly compacted snow, $\bullet$ : compacted snow; $\circ$ : granular snow. 
increased with track length. This result confirms the similar results of Maeno and others (1987) who investigated the formation mechanism and deposition patterns of snow avalanche debris using a mini-avalanche system constructed in a cold laboratory.

The deposition pattern was assumed to be similar in the case of the avalanche at the Makunosawa valley, and the snow water equivalent of debris was approximated by a quadratic expression on the distance from the farthest reach of the debris, based on the observed data in this study. The approximated values of snow water equivalent multiplied by the area of the runout zone gave a deposition mass of $10 \times 10^{7} \mathrm{~kg}$. Since the base snow-water equivalents of debris were measured along the longitudinal center line of the runout zone and the debris was considered to be thicker in the center, this value of $10 \times 10^{7} \mathrm{~kg}$ may be an overestimate. Assuming that the debris thickness was highest at the center and fell to zero at the lateral edges of debris, the deposition mass might be underestimated at $5 \times 10^{7} \mathrm{~kg}$. Consequently, the deposition mass of the avalanche was roughly estimated at $5-10 \times 10^{7} \mathrm{~kg}\left(1-2 \times 10^{5} \mathrm{~m}^{3}\right.$ based on the mean density of debris, $463 \mathrm{~kg} \mathrm{~m}^{-3}$ ).

\section{Avalanche velocity estimation in the cedar forest}

Based on the investigation results, the avalanche velocity was estimated from the bending stress of the broken cedar trees. Generally, three layers can be distinguished in the well-developed, full-size dry-snow avalanches: a dense-flow layer at the bottom with a density of $\sim 300 \mathrm{~kg} \mathrm{~m}^{-3}$; the saltation layer with a density of $\sim 30 \mathrm{~kg} \mathrm{~m}^{-3}$ above or ahead of the dense layer; and the suspension layer with a density of $<10 \mathrm{~kg} \mathrm{~m}^{-3}$ above and behind the saltation layer (Issler, 2003).

The dense-flow layer contains snow blocks, and the suspension layer consists of small snow grains. There is a fairly clear interface, rather than a gradual transition, between the dense core and the powder snow avalanche. The height of the powder snow layer can be $200 \mathrm{~m}$ or more, while the thickness of the dense-flow layer was less than $\sim 2 \mathrm{~m}$ and large shear rates were found in the dense-flow layer (Gubler, 1987; Nishimura and Ito, 1997; Kern and others, 2009).

Snow blocks were found in the debris in the runout zone, and the avalanche seemed to reach $\sim 17 \mathrm{~m}$ height at the upper edge of the cedar forest. We estimate the avalanche velocity assuming two layers: the dense-flow layer and the powder snow layer. The velocities of the two layers are assumed to coincide.

It was considered that the cedar trees broke as a result of bending, not shear stress, as the ends of the broken trunks were roughly split (Fig. 6). A tree is considered to break when the bending stress exceeds the modulus of rupture (MOR) of the tree. The MOR of the cedar trees in the Makunosawa valley was unknown, so the measurement value for Japanese cedar trees of $30 \pm 5 \mathrm{MPa}$ (Nakatani, 1991) was adopted. Assuming the trunk is a column with diameter $D(\mathrm{~m})$, the maximum bending stress, $\sigma\left(\mathrm{N} \mathrm{m}^{-2}\right)$, is expressed as

$$
\sigma=\frac{M}{Z}
$$

where $M(\mathrm{Nm})$ is the bending moment and $Z\left(\mathrm{~m}^{3}\right)$ is the section modulus. The section modulus is directly related to the strength of a corresponding shape of section. In the case

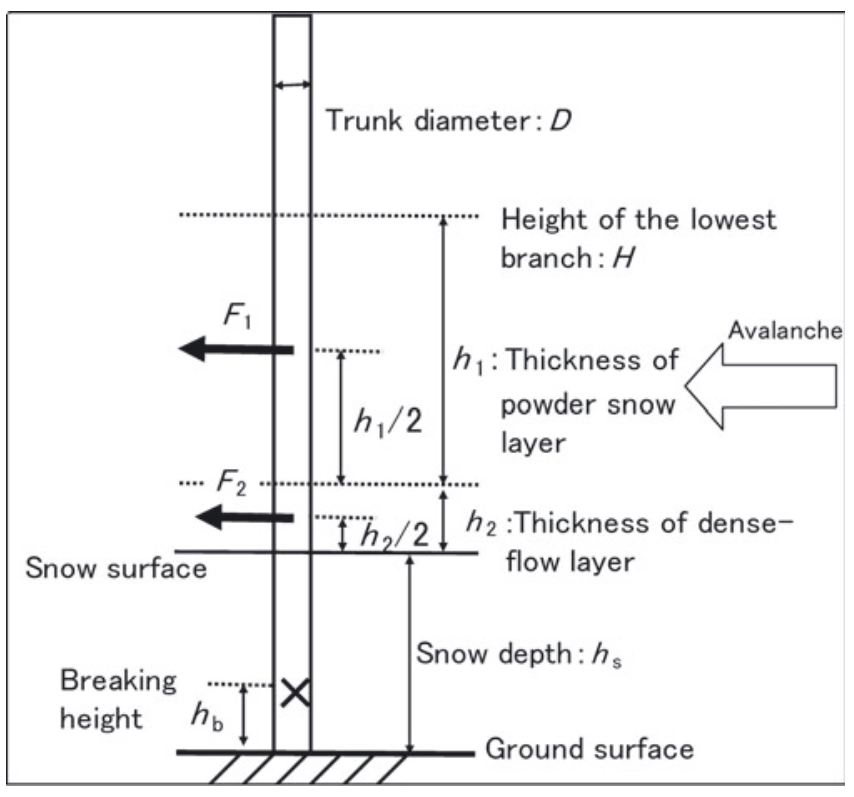

Fig. 12. Schematic of load on trunks from avalanche.

of a circle section, section modulus can be obtained by

$$
Z=\frac{\pi}{32} D^{3} \text {. }
$$

The avalanche force on the trunk, $F(\mathrm{~N})$, is expressed as

$$
F=\frac{1}{2} C_{\mathrm{d}} \rho A v^{2}
$$

where $A\left(\mathrm{~m}^{2}\right)$ is the area of the vertical section $(A=D h ; h(\mathrm{~m})$ is flow thickness), $C_{\mathrm{d}}$ is the drag coefficient, $\rho\left(\mathrm{kg} \mathrm{m}^{-3}\right)$ is the avalanche density and $v\left(\mathrm{~m} \mathrm{~s}^{-1}\right)$ is the avalanche velocity. In this case, the sum of the bending moments of the two layers, $M_{1}$ and $M_{2}$, caused by $F_{1}$ and $F_{2}$, operates on the breaking height, $h_{\mathrm{b}}(\mathrm{m})$, of the trunk (Fig. 12). The avalanche was assumed to flow on the snow surface, the height of which, $h_{\mathrm{s}}$ was $3.8 \mathrm{~m}$. The force received from the snowpack was regarded as negligible. The bending moments, $M_{1}(\mathrm{~N} \mathrm{~m})$ and $M_{2}(\mathrm{Nm})$, operating on the breaking height, $h_{\mathrm{b}}(\mathrm{m})$, are expressed as

$$
\begin{gathered}
M_{1}=F_{1}\left(\frac{h_{1}}{2}+h_{2}+h_{\mathrm{s}}-h_{\mathrm{b}}\right) \\
M_{2}=F_{2}\left(\frac{h_{2}}{2}+h_{\mathrm{s}}-h_{\mathrm{b}}\right) .
\end{gathered}
$$

The thickness of the powder snow layer, $h_{1}(\mathrm{~m})$, is obtained by deducing snow depth, $h_{\mathrm{s}}(\mathrm{m})$, and the thickness of the dense-flow layer, $h_{2}(\mathrm{~m})$, from the height of the lowest branch, $H(\mathrm{~m})$, as

$$
h_{1}=H-h_{\mathrm{s}}-h_{2} \text {. }
$$

The value of $h_{2}$ was unknown, so it was assumed to be 1 or $2 \mathrm{~m}$, because the debris thickness observed near the forest was $\sim 2 \mathrm{~m}$ (Fig. 5) and the large shear rate at the bottom layer was found to be below $2 \mathrm{~m}$ (Gubler, 1987; Nishimura and Ito, 1997; Kern and others, 2009).

When $F_{1}(\mathrm{~N})$ and $F_{2}(\mathrm{~N})$ obtained by Equation (3) are substituted into Equations (4) and (5), the bending moments, $M_{1}(\mathrm{Nm})$ and $M_{2}(\mathrm{Nm})$, can be expressed as the function of avalanche velocity, $v\left(\mathrm{~m} \mathrm{~s}^{-1}\right)$, as shown by Equations (7) and (8). The drag coefficient, $C_{\mathrm{d}}$, was given as 1.2 following Kashiyama (1967), Johnson and others (1982) 

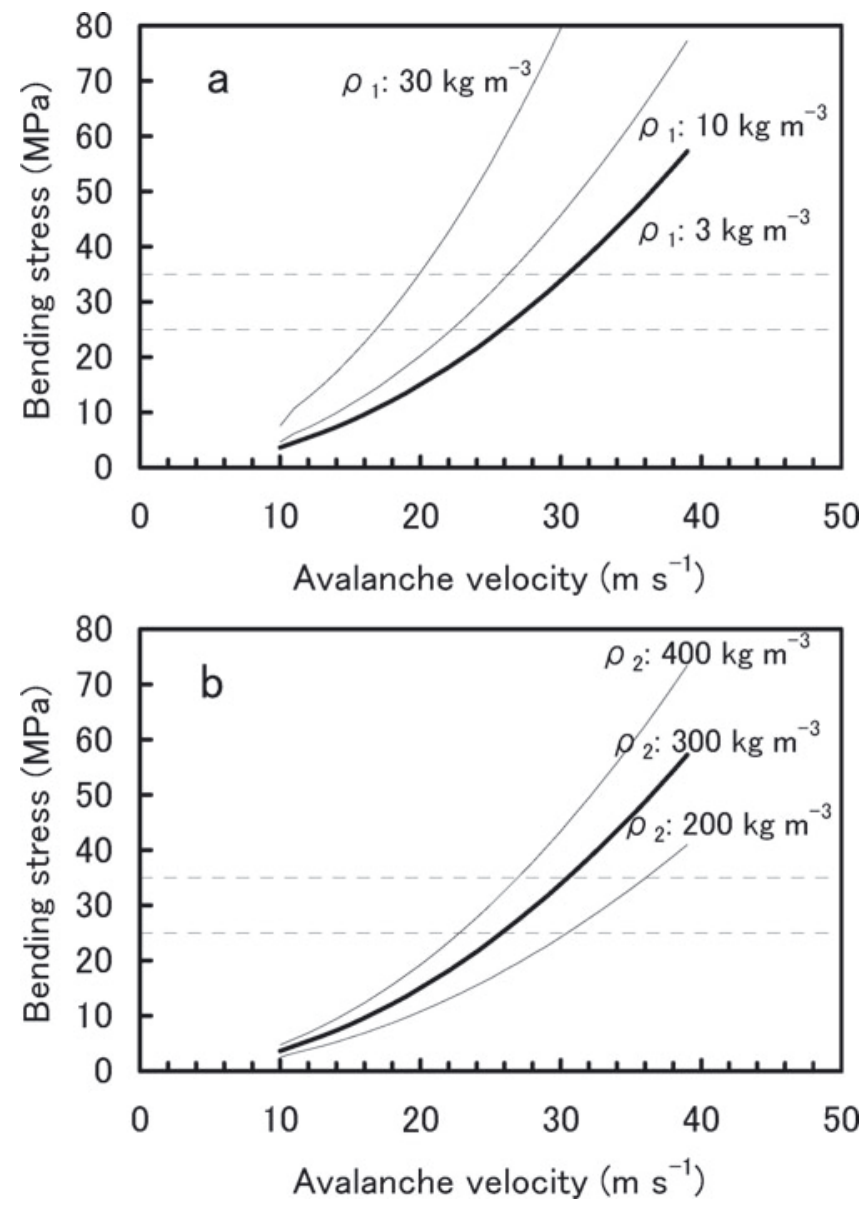

Fig. 13. Relationship between avalanche velocity and the bending stress on the trunk with $0.70 \mathrm{~m}$ diameter. The range of MOR $(30 \pm 5 \mathrm{MPa})$ is shown by the dotted lines. (a) The density of the powder snow layer, $\rho_{1}$, is 3,10 and $30 \mathrm{~kg} \mathrm{~m}^{-3}$, and the density of the dense-flow layer, $\rho_{2}$, is fixed at $300 \mathrm{~kg} \mathrm{~m}^{-3}$. (b) $\rho_{1}$ is fixed at $3 \mathrm{~kg} \mathrm{~m}^{-3}$, and $\rho_{2}$ is 200,300 and $400 \mathrm{~kg} \mathrm{~m}^{-3}$.

and Shi-igai (1993).

$$
\begin{gathered}
M_{1}=\frac{1}{4} C_{\mathrm{d}} \rho_{1} D h_{1} v^{2}\left(h_{1}+2 h_{2}+2 h_{\mathrm{s}}-2 h_{\mathrm{b}}\right) \\
M_{2}=\frac{1}{4} C_{\mathrm{d}} \rho_{2} D h_{2} v^{2}\left(h_{2}+2 h_{\mathrm{s}}-2 h_{\mathrm{b}}\right)
\end{gathered}
$$

Using these equations, (1) the initial velocity of the avalanche flowing into the forest and (2) the deceleration in the forest were calculated. To estimate the initial velocity flowing into the forest, the bending stress on the trunk with a $0.70 \mathrm{~m}$ diameter was calculated since this was the largest diameter among the broken trunks near the upper edge of the forest (Fig. 9). The breaking height, $h_{\mathrm{b}}(\mathrm{m})$, of the trunk was $0.5 \mathrm{~m}$ according to observation. Avalanche velocities for various densities $\left(\rho_{1}\right.$ is 3,10 and $30 \mathrm{~kg} \mathrm{~m}^{-3}, \rho_{2}$ is 200, 300 and $400 \mathrm{~kg} \mathrm{~m}^{-3}$ ) were calculated, assuming $h_{2}(\mathrm{~m})$ to be $2 \mathrm{~m}$. Because the distance, $x(\mathrm{~m})$, from the upper edge of the forest to the broken trunk was $4 \mathrm{~m}, H(\mathrm{~m})$ was set at $16.7 \mathrm{~m}$ following Equation (10).

The relationships between the bending stress and the initial velocity of the avalanche for various densities are shown in Figure 13. Assuming $\rho_{1}=3 \mathrm{~kg} \mathrm{~m}^{-3}$ and $\rho_{2}=300 \mathrm{~kg}$ $\mathrm{m}^{-3}$, the initial velocity of flow into the cedar forest is estimated from the figure to be at least $26-31 \mathrm{~m} \mathrm{~s}^{-1}$.

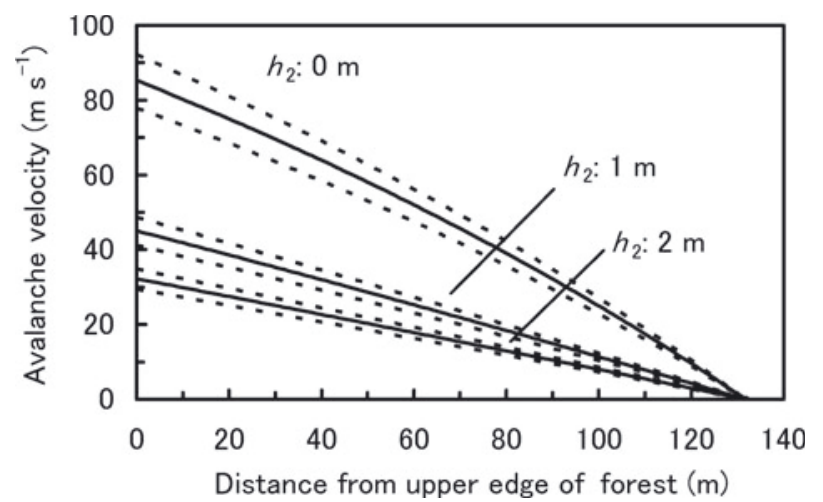

Fig. 14. Avalanche velocities in the forest calculated in three cases (the thickness of the dense-flow layer, $h_{2}$, is 2,1 and $0 \mathrm{~m}$ ). The densities of powder snow and dense-flow layers $\left(\rho_{1}\right.$ and $\left.\rho_{2}\right)$ were assumed to be 3 and $300 \mathrm{~kg} \mathrm{~m}^{-3}$. The MOR was given as $30 \mathrm{MPa}$, and the dotted lines indicate the results of MOR fluctuation $(30 \pm 5 \mathrm{MPa})$.

This result was compared with previous works. Examples of peak velocities for large-scale dry snow avalanches are $18-35 \mathrm{~m} \mathrm{~s}^{-1}$ at Rogers Pass, Canada, 23-49 $\mathrm{m} \mathrm{s}^{-1}$ for 12 dry snow avalanches at Ryggfonn, Norway, and up to $65 \mathrm{~m} \mathrm{~s}^{-1}$ in the Aulta path in Switzerland (Issler, 2003). For the Makunosawa valley avalanche in 2001, the mean velocity was $\sim 40 \mathrm{~m} \mathrm{~s}^{-1}$ from the tremor of the geophone (Takeuchi and others, 2003). The 1984 avalanche was simulated and the velocity was calculated at $\sim 30 \mathrm{~m} \mathrm{~s}^{-1}$ near the upper edge of the cedar forest (Abe and others, 1987). The velocity obtained in this study seems to be a reasonable value.

To estimate the avalanche deceleration, the trunk diameter, $D(\mathrm{~m})$, at breaking height was given by Equation (9) because $D(\mathrm{~m})$ decreased with the distance $x(\mathrm{~m})$ like the line in Figure 9. $H(\mathrm{~m})$ was given by Equation (10) like the line in Figure 8 . This line connects the maximum $H$ in the area with $x \leq 70 \mathrm{~m}$, because $97 \%$ of the broken trunks are located in the area where $x \leq 70 \mathrm{~m}$ (Fig. 9).

$$
\begin{gathered}
D=-0.0055 x+0.724 \\
H=-0.027 x+16.8
\end{gathered}
$$

The $h_{\mathrm{b}}(\mathrm{m})$ was fixed at $1.2 \mathrm{~m}$ which is the mean of all measurements. Avalanche velocities were calculated in three cases in which $h_{2}=2,1$ and $0 \mathrm{~m}$, assuming $\rho_{1}=3 \mathrm{~kg} \mathrm{~m}^{-3}$ and $\rho_{2}=300 \mathrm{~kg} \mathrm{~m}^{-3}$.

Decreases in avalanche velocity in the forest are shown in Figure 14 . The velocity was estimated to be larger with a smaller $h_{2}$, because the contribution to the bending moment of the dense-flow layer with high density is larger than that of the powder snow layer with low density. In this calculation, $H(\mathrm{~m})$ was given by Equation (10) and this approximate line does not coincide with the observed $H$ in the area with $x>70 \mathrm{~m}$ (Fig. 8). However, this influence on the calculated velocity was confirmed to be very small. In this calculation, the thickness of the dense-flow layer was fixed at 1 or $2 \mathrm{~m}$, and the difference of $H$ came to be the difference in the thickness of the powder snow layer. As the density of the powder snow layer is small, the bending moment of the layer to the trunk is small. Therefore the influence on the calculated results was small. The height of the lowest branch lowered abruptly $\sim 70 \mathrm{~m}$ from the upper edge of the forest. This may show that the branches were 
broken by the dense-flow layer in the area with $x>70 \mathrm{~m}$, while they were broken by both layers in the area before $70 \mathrm{~m}$. The velocity decreased to $0 \mathrm{~m} \mathrm{~s}^{-1} \sim 130 \mathrm{~m}$ from the upper edge of the forest in any case of $h_{2}$. This result was caused by the decrease in $D(\mathrm{~m})$ as shown by Equation (9), but this position where the velocity became $0 \mathrm{~m} \mathrm{~s}^{-1}$ coincided with the observation.

\section{CONCLUDING REMARKS}

We obtained a dataset on a large-scale dry slab avalanche and forest damage in the Makunosawa valley. The avalanche on 17 February 2008 was one of the largest observed in the valley; the horizontal runout distance was $\sim 3000 \mathrm{~m}$, the area of the runout zone was $\sim 10$ ha and the mass of debris was $5-10 \times 10^{7} \mathrm{~kg}\left(1-2 \times 10^{5} \mathrm{~m}^{3}\right)$. The sliding surface of the avalanche was presumed to be the faceted snow which formed at $2 \mathrm{~m}$ height according to the snowpack model simulation. The avalanche was estimated to flow into the cedar forest at a velocity of $>26-31 \mathrm{~m} \mathrm{~s}^{-1}$, with a $17 \mathrm{~m}$ high suspension layer and a dense-flow layer $<2 \mathrm{~m}$ in height. It slowed down in the forest, and stopped $\sim 130 \mathrm{~m}$ after penetrating the upper edge of the forest.

We attempted to calculate the avalanche velocity in the forest from the bending stress of the broken cedar trees and obtained a reasonable deceleration of the avalanche. However, the cause for the avalanche stopping there may be not only the resistance of the forest but also the terrain of the valley. Had the cedar forest not existed there and had the avalanche reached further, the effects of the forest in reducing the avalanche velocity would have been confirmed. To understand the decelerating effects of forests, a numerical simulation of an avalanche over the terrain of the Makunosawa valley with and without forest would be useful. This study will help such a numerical simulation in the future.

In this study, only the bending stress was considered and the force of the avalanche was assumed to operate on the trunk with constant pressure. Consideration of a more complex process such as shear stress by a large shear rate and impact force by snow blocks in the dense flow layer will be a future work.

\section{ACKNOWLEDGEMENTS}

The survey and investigations on the snow avalanche and forest damage were supported by K. Izumi, I. Kamiishi, K. Kawashima, S. Yamaguchi, N. Miyazaki, E. Podolskiy, T. Suzuki, T. Sakamoto, H. Hagino, Y. Goto, S. Murakami and Y. Endo. This study could not have been carried out without their support, for which we are very grateful. We also thank the scientific editor, P. Bartelt, for his useful suggestions on the manuscript and very kind encouragement. Part of this study was financially supported by a Grantin-Aid for Scientific Research (project No. 22510199) from the Ministry of Education, Culture, Sports, Science and Technology of Japan.

\section{REFERENCES}

Abe, O., T. Nakamura, T.E. Lang and T. Ohnuma. 1987. Comparison of simulated runout distances of snow avalanches with those of actually observed events in Japan. IAHS Publ. 162 (Symposium at Davos 1986 - Avalanche Formation, Movement and Effects), 463-473.
Abe, O. and 7 others. 2006. Shear strength of natural and artificial depth hoar layers. In Gleason, J.A., ed. Proceedings of the International Snow Science Workshop, 1-10 October 2006, Telluride, Colorado. Marmot, CO, International Snow Science Workshop, 7-14.

Bartelt, P. and M. Lehning. 2002. A physical SNOWPACK model for the Swiss avalanche warning. Part I: numerical model. Cold Reg. Sci. Technol., 35(3), 123-145.

Bartelt, P. and B.W. McArdell. 2009. Granulometric investigations of snow avalanches. J. Glaciol., 55(193), 829-833.

Bartelt, P. and V. Stöckli. 2001. The influence of tree and branch fracture, overturning and debris entrainment on snow avalanche flow. Ann. Glaciol., 32, 209-216.

Christen, M., P. Bartelt and J. Kowalski. 2010. Back calculation of the In den Arelen avalanche with RAMMS: interpretation. Ann. Glaciol., 51(54), 161-168.

Gubler, H. 1987. Measurements and modelling of snow avalanche speeds. IAHS Publ. 162 (Symposium at Davos 1986 - Avalanche Formation, Movement and Effects), 405-420.

Gubler, H. and J. Rychetnik. 1991. Effects of forests near the timberline on avalanche formation. IAHS Publ. 205 (Symposium at Vienna 1991 - Snow, Hydrology and Forests in High Alpine Areas), 19-38.

Hirashima, H, K. Nishimura, S. Yamaguchi, A. Sato, and M. Lehning. 2008. Avalanche forecasting in a heavy snowfall area using the SNOWPACK model. Cold Reg. Sci. Technol., 51(2-3), 191-203.

likura, S., K. Kawashima, T. Endo and T. Fujii. 2000. Snow avalanche detection and alarm system using a vibration sensor. Seppyo, J. Jpn. Soc. Snow Ice, 62(4), 367-374. [In Japanese with English summary.]

In der Gand, H. 1981. Stand der Kenntnisse über Schnee und Lawinen in Beziehung zum Wald in Europa. In Proceedings of the XVII IUFRO World Congress, 6-12 September 1981, Kyoto, Japan. Kyoto, International Union of Forestry Research Organizations, 319-337.

Issler, D. 2003. Experimental information on the dynamics of dry-snow avalanches. In Hutter, K. and N. Kirchner, eds. Dynamic response of granular and porous materials under large and catastrophic deformations. Berlin, Springer, 109-160. (Lecture Notes in Applied and Computational Mechanics 11.)

Johnson, R.C., Jr, G.E. Ramey and D.S. O'Hagan. 1982. Wind induced forces on trees. J. Fluid Eng., 104, 25-39.

Kashiyama, T. 1967. Comparative studies of avalanche injury and wind damage to forests. Seppyo, J. Jpn. Soc. Snow Ice, 29(4), 11-13. [In Japanese with English summary.]

Kern, M., P. Bartelt, B. Sovilla and O. Buser. 2009. Measured shear rates in large dry and wet snow avalanches. J. Glaciol., 55(190), 327-338.

Lehning, M., P. Bartelt, B. Brown, C. Fierz and P. Satyawali. 2002a. A physical SNOWPACK model for the Swiss avalanche warning. Part II: snow microstructure. Cold Reg. Sci. Technol., 35(3), 147-167.

Lehning, M., P. Bartelt, B. Brown and C. Fierz. 2002b. A physical SNOWPACK model for the Swiss avalanche warning. Part III: meteorological forcing, thin layer formation and evaluation. Cold Reg. Sci. Technol., 35(3), 169-184.

Maeno, N., R. Naruse and K. Nishimura. 1987. Physical characteristics of snow-avalanche debris. IAHS Publ. 162 (Symposium at Davos 1986 - Avalanche Formation, Movement and Effects), 421-427.

McClung, D. and P. Schaerer. 2006. The avalanche handbook. Third edition. Seattle, WA, The Mountaineers.

Nakatani, H. 1991. Structural mechanics study on the damage of tree stems caused by accumulating in the crown. J. Toyoma Forest. Forest Prod. Res. Cent., 4, 1-54. [In Japanese with English summary.]

Nishimura, K. and Y. Ito. 1997. Velocity distribution in snow avalanches. J. Geophys. Res., 102(B12), 27,297-27,303. 
Saeki, M. 1975. Damage to Japanese cedar forest by surface avalanche. Seppyo, J. Jpn. Soc. Snow Ice, 37(3), 37-41. [In Japanese with English summary.]

Shi-igai, H. 1993. On the hydrodynamical drag coefficient of trees. Nagare [J. Jpn Soc. Fluid Mech.], 12, 11-19. [In Japanese with English summary.]

Shimokawa, K. 1983. Avalanche research based on dendroindicator in the Tanigawa Massif. Seppyo, J. Jpn. Soc. Snow Ice, 45(3), 143-150. [In Japanese with English summary.]

Sovilla, B., F. Sommavilla and A. Tomaselli. 2001. Measurements of mass balance in dense snow avalanche events. Ann. Glaciol., 32, 230-236.

Takeuchi, Y. 2010. Recent land slide hazards: the large-scale avalanches at Makunosawa valley in Myoko. Water Science, 54(4), 39-57. [In Japanese.]

Takeuchi, Y., K. Akiyama and M. Irasawa. 2002. Avalanche detection and meteorological observations at Makunosawa valley in Myoko, Japan. Mater. Glyatsiol. Issled./Data Glaciol. Stud. 93, 126-132.
Takeuchi, Y., K. Yamanoi, Y. Endo, S. Murakami and K. Izumi. 2003. Velocities for the dry and wet snow avalanches at Makunosawa valley in Myoko, Japan. Cold Reg. Sci. Technol., 37, 483-486.

Takeuchi, Y. and 11 others. 2009. The large-scale dry slab avalanche of February 2008 at Makunosawa valley in Myoko, Japan. Seppyo, J. Jpn. Soc. Snow Ice, 71(3), 167-176. [In Japanese with English summary.

Takeuchi, Y. and others. 2010. Study of extent of damage to cedar forest by large-scale slab avalanche, and estimation of the avalanche velocity at Makunosawa, Myoko, Japan. Seppyo, J. Jpn. Soc. Snow Ice, 72(2), 115-125.

Vallet, J., U. Gruber and F. Dufour. 2001. Photogrammetric avalanche volume measurements at Vallée de la Sionne, Switzerland. Ann. Glaciol., 32, 141-146.

Yamanoi, K. and Y. Endo. 2002. Dependence of shear strength of snow cover on density and water content. Seppyo, J. Jpn. Soc. Snow Ice, 64(4), 443-451. [In Japanese with English summary.] 